\title{
Determination of Optimum Percentage Addition of Magnesium in 319 Aluminum Alloy
}

\author{
Vivek K Ravi ${ }^{1}$, Aswin $\mathrm{S}^{2}$, Vineesh Vishnu ${ }^{3}$, Prajith $\mathrm{P}^{4}$ \\ 1, 2, 3,4 (Department Of Mechanical Engineering, Sri Vellappally Natesan College of Engineering, India)
}

\begin{abstract}
The use of aluminum and magnesium alloys in the automobile industry is continuously increasing. The driving force is reduced green house gas emissions resulting from light weighting of the vehicles and efficient scrap recycling. The aluminium alloy castings are generally used in automotive, aerospace, defense and general engineering industries. Among the commercial aluminium castings, $\mathrm{Al}-6 \mathrm{Si}-3 \mathrm{Cu}(319)$ is widely used mainly because of its excellent cast ability, high strength to weight ratio, good mechanical properties, lower coefficient of thermal expansion, low recycling cost and corrosion resistance. The present study was performed on $319 \mathrm{Al}$ alloy to investigate the effect of magnesium addition as well as other melt treatment parameters such as Sr modification and grain refinement on the heat treatment behavior of the alloy. T6 treatment was carried out on the alloy taking an optimum temperature of $500^{\circ} \mathrm{C}-10$ hours, for solution treatment followed by $60^{\circ} \mathrm{C}$ water quenching and $170^{\circ} \mathrm{C}$ 8 hours for artificial ageing. The results show that increasing the Mg content in Al 319 up to $0.45 \%$ considerably enhances the alloy response to heat treatment in the T6 temperatures. Addition of Mg in amounts of the order of $0.45 \%$ results in the precipitation of $\mathrm{Al}_{5} \mathrm{Mg}_{8} \mathrm{Si}_{6} \mathrm{Cu}_{2}$ phase particles. Modification with $\mathrm{Sr}$ tends to cause severe segregation of Cu-containing intermetallics in areas away from the growing Si regions. Various tests like tensile, fatigue, wear and hardness are done on the various castings and the results are compared.

Keywords: Aluminium 319 alloy, Sr modification, water quenching, tensile test, grain refinement.
\end{abstract}

\section{Introduction}

Al-Si alloys are materials that have been developed over the years to meet the increasing demands of the automotive industry for smaller, lighter-weight, high-performance components. An important alloy in this respect is the 319 alloy, wherein silicon and copper are the main alloying elements, and magnesium is often added in automotive versions of the alloy for strengthening purposes. The excellent castability and mechanical properties of 319 aluminum alloy makes it a popular foundry alloy for use in automotives applications. Its low specific gravity is essential to reduce energy consumption and its excellent corrosion resistance and low costs of recycling are also important considerations from an environmental point of view. The presence of magnesium improves strain, hardenability and enhances the material strength by solid solution. Chemical composition and Heat treatment exert an important influence on the mechanical properties. The most applied heat treatment for this alloy is a solution treatment followed by an age-hardening that is required for the precipitation of the $\mathrm{Al} 2 \mathrm{Cu}$ hardening constituent. Solution heat treatment is particularly suitable for alloys with high magnesium content in order to promote the formation of the important strengthening precipitate, $\mathrm{Mg}_{2} \mathrm{Si}$, a hardening peak caused by a cooperative precipitation of $\mathrm{Al}_{2} \mathrm{Cu}$ and $\mathrm{Mg}_{2} \mathrm{Si}$ phases in this kind of alloys. It has been found that precipitation in the Al-Cu$\mathrm{Mg}-\mathrm{Si}$ alloys depends on magnesium con-tents as well as on the $\mathrm{Cu}$ : $\mathrm{Mg}$ ratio in solid solution. The mechanical properties of 319 alloy are generally influenced by the micro structural characteristics and casting defects.

The factors determining the microstructure are the compositions, the solidification condition and heat treatment. The microstructure of 319 is controlled by its chemical composition and also by the addition of modifiers and grain refiners. The grain refiners (Al-Ti-B) reduce the grain size whereas the modifier like strontium alters the shape of eutectic Si from acicular brittle form to fibrous form. $\mathrm{Sr}$ is used because its effect does not fade on holding and gives better modification even during remelting.

The liquid aluminum is prone to hydrogen adsorption and oxidation. Gas porosity and oxide inclusion are inevitably found in $\mathrm{Al}$ castings. In addition, if the castings is not properly fed, shrinkage porosity results which is quite deleterious to mechanical and fatigue properties. The fatigue behavior of the alloy depends on number of factors such as mechanical loading and micro structural factors particularly presence of porosity introduced by the combined effect of dissolved gas and shrinkage. Factors controlling porosity formation are the hydrogen content, solidification rates and alloy treatments such as strontium modification, grain refinement and melt cleanliness.

In the present study, 319 alloy plate, finger and cylindrical castings were made in permanent mould by adding different additives like $\mathrm{Sr}(0.02 \%)$, tib $(0.6 \%), \mathrm{Mg}(0.2,0.4,0.6,0.45) \%$ All the castings were subjected to T6 heat treatment conditions. The heat treatment cycle for aluminum alloys involves solutionizing the material by holding it at a temperature slightly below the eutectic temperature. This helps to dissolve the various intermetallic phases that are formed, homogenize the matrix and spherodises the eutectic silicon particles it is done at an optimum temperature of $500^{\circ} \mathrm{C}$ for 10 hours. The material is then quenched, typically in water at $70^{\circ} \mathrm{C}$, to form a 
supersaturated solid solution. Ageing follows at $170^{\circ} \mathrm{C}$ for 8 hours for uniform distribution of small precipitates.

The effect of the various additives on the microstructure and the mechanical properties like hardness, tensile, fatigue and wear were studied. Tensile and fatigue samples specimens were machined according to ASTM standards. The specimens were subjected to tensile and fatigue test at room temperature. Microstructure of the as cast and heat treated samples were analyzed using an optical microscope to study the silicon morphology. To understand the mode of fracture and contribution of microstructural and porosity towards fatigue property, fractographic examinations on the fractured surface were carried out using scanning electron microscope.

\subsection{Procedure for melting}

\section{EXPERIMENTAL DETAILS}

About $10 \mathrm{Kg}$ of alloy ingots were cut into suitable sizes for charging into the crucible. The cut pieces are first mechanically cleaned using acetone. The ingots were preheated before charging for melting. Mild steel tools which come into contact with molten metal were suitably coated with frit and dried properly by heating. The furnace and ovens were periodically checked for rate of heating and set temperature. When the crucible kept in the furnace attains $700-750^{\circ} \mathrm{C}$, the preheated ingots were charged into it. Half of the coverall flux (preheated to 120$130^{\circ} \mathrm{C}$ ) was sprinkled over the charge during the time of charging itself. The remaining half of the flux was sprinkled when the charge was just melting. The temperature of the melt was measured and monitored using Chromel-Alum el thermocouple.

\subsubsection{Nitrogen Degassing}

Nitrogen from the cylinder was dried by bubbling the gas through concentrated sulphuric acid and anhydrous calcium chloride. The dry nitrogen was bubbled into the molt en metal through multiple holes in a graphite lance for about $40-60$ minutes. The temperature of the melt was maintained at $740+10^{\circ} \mathrm{C}$ throughout the degassing treatment.

\subsubsection{Modification}

In order to change the shape of eutectic silicon from acicular to fine and fibro us form, various additives are used. These are preheated to $150^{\circ} \mathrm{C}$ and plunged into the melt and held for 10 minutes for complete dissolution and homogenization of the melt.

\subsubsection{Details of mould used}

Various metal moulds like bottom pouring, cylindrical, plate and finger moulds were used for the castings.

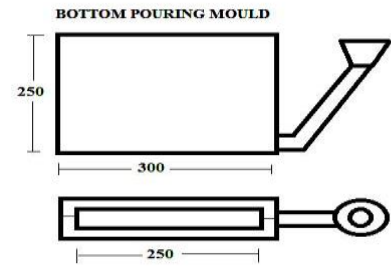

all dimensions in mm
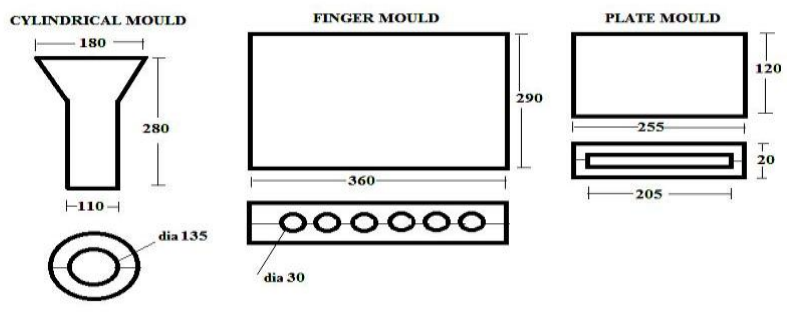

\subsection{4 pouring}

Fig.1. Moulds

After degassing, the melt is subjected to modification treatment and the slag on the top of the melt was removed. It is then poured into the preheated moulds. The pouring temperature is kept at $720-730^{\circ} \mathrm{c}$. The casting is removed after solidification.

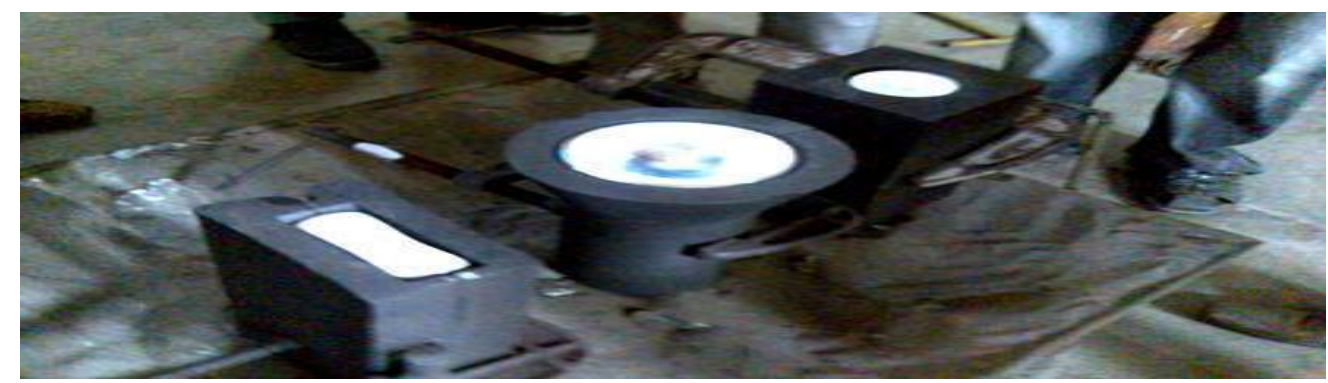

Fig: 2. Pouring of molten metal into the moulds 


\subsection{Metallography}

\subsubsection{Preparation Of Specimen}

The specimens for metallographic studies are machined out from the various castings with $10 \mathrm{~mm}$ diameter and $15 \mathrm{~mm}$ height. The metallographic specimens are shown in fig.3.

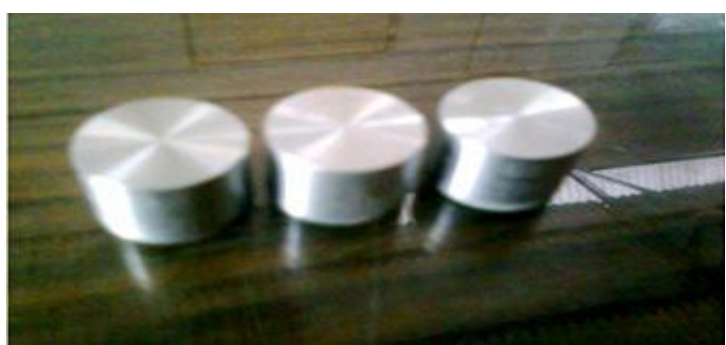

Fig: 3. Metallographic specimen

\subsubsection{Fine Grinding}

The specimen was hand rubbed against the abrasive emery paper, which is laid over a flat glass plate. 3 grades of abrasives are used: 220 grit, 400 grit and 600 grit. The specimen was first ground on 220 grit paper, so that scratches are produced at right angles to those initially existing on the specimen which was produced during preliminary grinding. After removing the primary grinding marks, the specimen was washed in running water. Grinding was continued on 400 grit, and again turning the specimen through $90^{\circ}$ and polished to remove previous scratch marks and the procedure repeated with 600 grit.

\subsubsection{Rough Polishing}

A very small quantity of diamond powder (particle size 6 microns) carried in a paste that is oil soluble is placed on the nylon cloth covered surface of a rotating polishing wheel. Kerosene was used during the polishing operation. Specimen was pressed against the cloth of a rotating wheel with considerable pressure and moved around the wheel in a direction opposite to rotation of the wheel to ensure uniform polishing. The process was repeated with diamond paste of 3 and 1 microns by changing the cloth.

\subsubsection{Final Polishing}

In final polishing, the fine scratches and very thin distorted layer remaining from the rough polishing were removed. The polishing compound used was diamond powder of particle size 0.25 micron carried in a paste that is oil soluble. The cloth used was velvet. Fine polishing makes the surface scratch free, with almost no detectable layer of distorted metal making the surface suitable for viewing under microscope.

\subsection{Heat Treatment}

As per ASTM standards tensile, fatigue, wear and hardness samples were machined out from the castings. The samples were then subjected to heat treatment according to the following steps: The samples were subjected to isothermal holding at $500^{\circ} \mathrm{C}$ for 10 hours in an air circulated chamber furnace. After solutionizing, the samples were immediately quenched in hot water at $60^{\circ} \mathrm{C}$. After that the samples were allowed to undergo natural ageing at room temperature for about $10-12$ hours and then artificially aged at $170^{\circ} \mathrm{C}$ for 8 hours in an air circulated oven and then cooled in air.

\subsection{Tensile testing}

The heat treated specimens were evaluated for its tensile properties. Gauge length of $25 \mathrm{~mm}$ was marked on the specimen. The tensile properties (ultimate tensile strength and \% elongation) at room temperature were measured using a servo- hydraulically controlled Universal Testing Machine (Instron model 1195). The ends of the specimen were gripped in the machine and load was applied till it fractures. After fracture, the two pieces of the broken specimen were placed as if together and the distance between two gauge marks at the place of fracture was measured. The change in gauge length divided by the original length gives the $\%$ elongation. The maximum load was measured from the data acquisition system connected to the personal computer. Using these values, yield strength and ultimate tensile strength was calculated. 


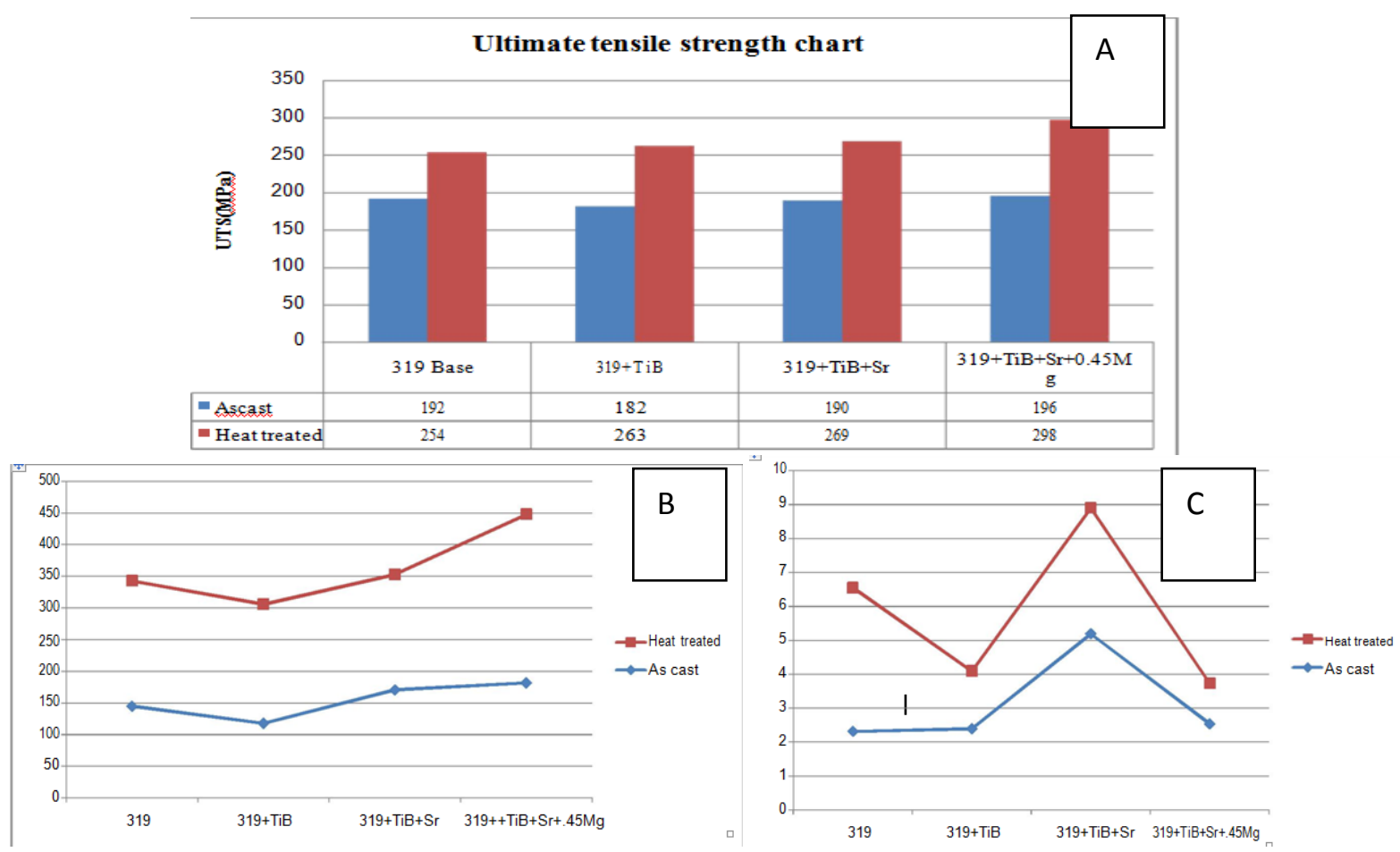

Fig.4.A) The Ultimate Tensile Strength B) Yield Strength And C) Elongation Plots Of Alloys

In T6-treated cast aluminium alloys, there exists a region during the early stage of solution treatment in which the elongation to fracture of alloy reaches minimum values. This is due to a timing mismatch between an increase in strength and the changes in the characteristics of the Si particles. The improvement of strength after the controlled precipitation of small matrix-strengthening precipitates during artificial aging is consistent. The reason for the increase in strength is primarily due to the precipitation of metastable $\beta-\mathrm{Mg}_{2} \mathrm{Si}$ precipitates from the supersaturated solid solution, which obstructs the movement of dislocations. Yield strength of the alloy with addition of $0.45 \mathrm{Mg}$ at T6 shows better results. After conducting the tensile test, the fractured sample is measured for its gage length for finding out the elongation .The percentage elongation shows that the magnesium addition decreases the percentage elongation .It's due to the formation of the brittle $Q$ phase in the aluminum matrix.

\subsection{Characterization}

\subsubsection{Microstructure}

\subsubsection{1319 base alloy (unmodified)}

As Cast
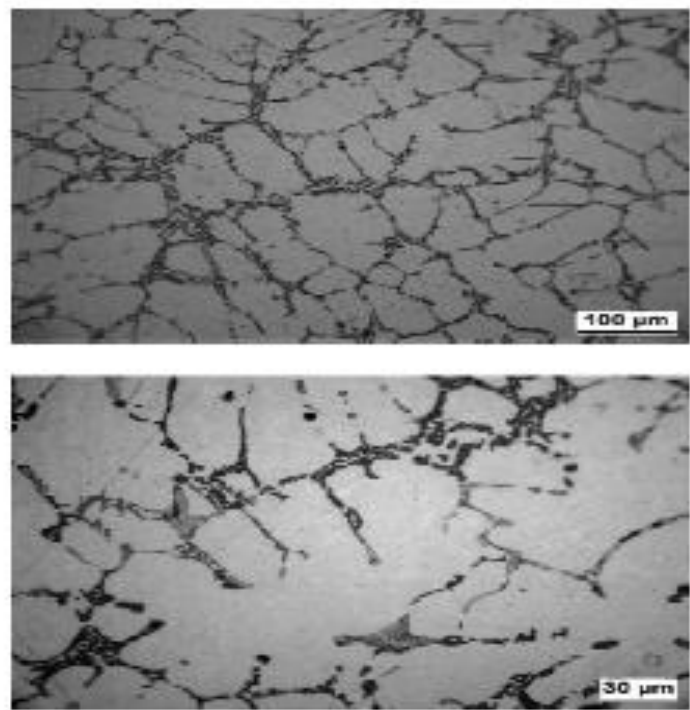

Heal Troatod.
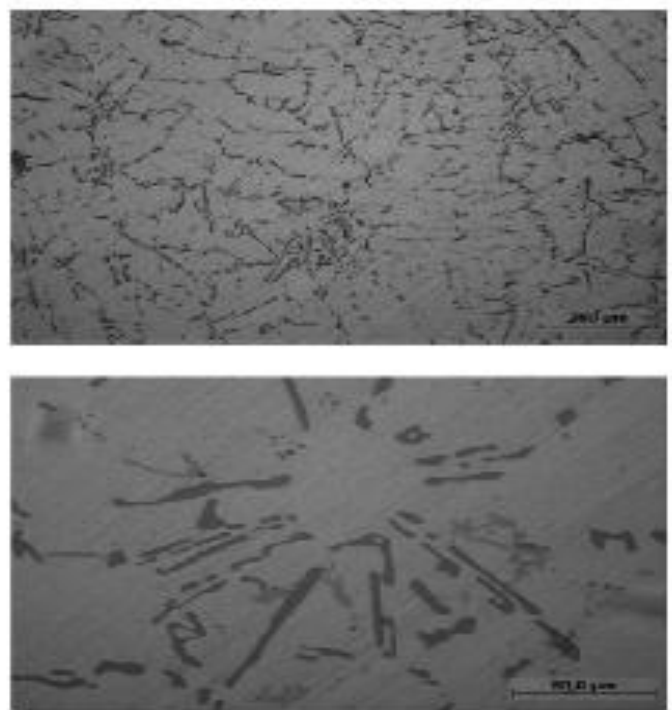

Fig.5. As Cast And Heat Treated 319 Base Alloy 
Fig.5 shows the microstructure of unmodified 319 alloy which consists mainly of a- aluminium network and alternate layers of eutectic aluminium and acicular eutectic silicon $n$ in the eutectic region between the dendritic arms. The morphology of modified eutectic sil icon is typically coarse and flanky. These needles are known to act as stress raisers in the micro structure making the material to fracture in a less ductile mode. In unmodified 319 alloys, a large number of eutectic grains nucleate at or near the primary aluminium dendrite tips, and eutectic aluminum forms epitaxial on the primary dendrites, also we can see the phases of $-\mathrm{A}_{2} \mathrm{Cu},-\mathrm{Al}_{5} \mathrm{FeSi}$ intermetallics [1]. By heat treatment it is seen that there is a change in the morphology of eutectic silicon. The needle like silicon structure is transformed to a more rounded off structure thus lowering the brittle nature.

\subsubsection{Modification of 319 using $\mathrm{Sr}$}

In the present study, $0.02 \%$ strontium was added to 319 alloy and cast in metal moulds. The microstructure reveals that addition of strontium modifies the coarse, acicular eutectic Si to finer, lamellar or fibrous structure depending on the modifiers. The most popular explanation suggests that the modifying element suppress the growth of silicon crystals within the eutectic, providing a finer lamellae distribution. The modified alloy has higher porosity content when compared to the base alloy. This indicates the role of hydrogen in the melt for porosity formation. With addition of $\mathrm{Sr}$, a dramatic decrease in the nucleation frequency of eutectic grains is observed, and the grains are nucleated independently of the primary phase at distribute $\mathrm{d}$ centers in the interdendritic regions. It was proposed that the addition of $\mathrm{Sr}$ poisons the nucleation sites for the $\beta-\mathrm{Al}_{5} \mathrm{FeSi}$ platelets and accelerates the dissolution process of the individual $\beta-\mathrm{Al}_{5} \mathrm{FeSi}$ segments by breaking them into two or more fragments. Theoretically, $\mathrm{Sr}$ addition is expected to be rejected by $\alpha-\mathrm{Al}$ and to cause a solute buildup at the primary dendrite-liquid interface during solidification. Solute buildup could then increase the nucleation of equi-axed eutectic colonies due to increased constitutional under cooling.

However, Sr addition was instead found to significantly decrease the number of eutectic grains. It is, therefore, more likely that the potency or number of effective nucleants for eutectic silicon in the melt was reduced. Strontium induces a generalized undercooling in the eutectic and displacement of the eutectic com position towards higher Si contents, thus making the alloy slightly hypoeutectic [2].
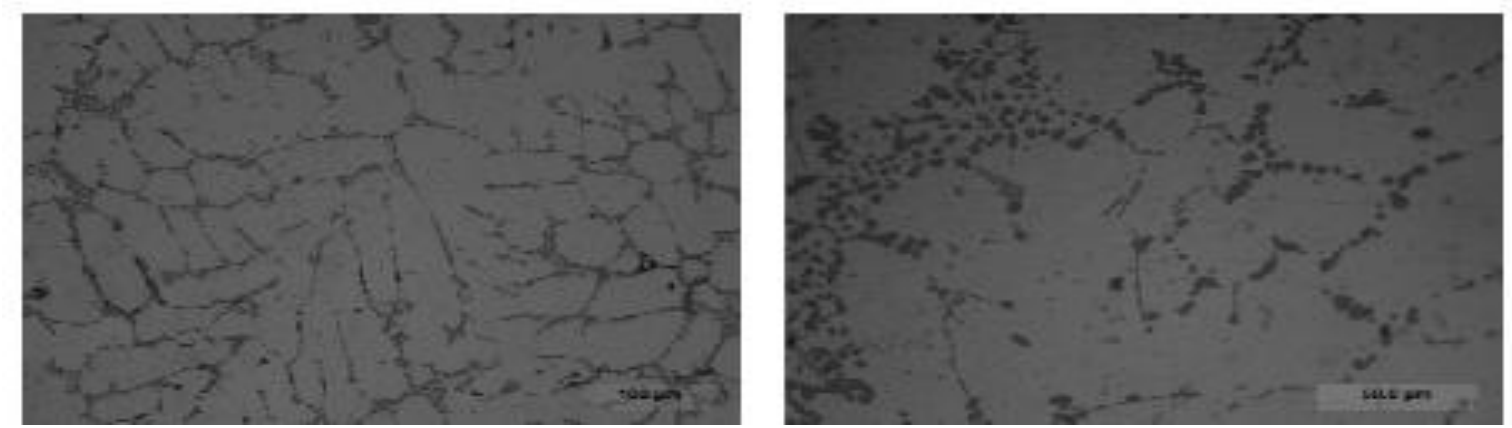

Fig.5. 319+Sr+Tib+Mg As Cast And Heat Treated

In hypoeutectic Al-Si alloys, it has been suggested that the decrease in the number of eutectic-nucleation events caused by $\mathrm{Sr}$ additions occurs due to poisoning of the extremely prolific nuclei-aluminium phosphide (alp) nucleant particles. However, while the exact mechanism responsible for the poisoning by $\mathrm{Sr}$ addition has not been confirmed, the formation of Sr-rich intermetallics, $\mathrm{Al}_{2} \mathrm{Si}_{2} \mathrm{Sr}$, in $\mathrm{Sr}$-modified alloys has been proposed to be a contributing factor. Moreover, $\mathrm{Al}_{2} \mathrm{Si}_{2} \mathrm{Sr}$ was found to surround the alp particles, which is a strong indication of the poisoning mechanism, i.e., the addition of Sr renders alp nuclei ineffective by forming a layer of intermetallic phase around them [1].

Finally, the main reason for targeting the modified $\mathrm{Si}$ and refined b-Al5FeSi components by the use of $\mathrm{Sr}$ is proposed to be the avoidance of the straightening of oxide bi-film cracks. These are initially compact and relatively harmless when first cast, since they are raveled by the turbulence of casting. However, the growth of (unmodified) $\mathrm{Si}$ or $\mathrm{b}-\mathrm{Al}_{5} \mathrm{FeSi}$ as platelets straightens the cracks, and thus lowers properties. The deactivation of the oxides as substrates means that they remain in their compact convoluted state, and thus reasonably (although not altogether) harmless.

The increase in the tensile properties of sand mould Sr-modified alloy compared to those of Na-modified alloy was $12.7 \%$ for the proof stress. $16.3 \%$ for the ductility and 33.3 for the toughness. For metal mould ingots, the increases were $16.7 \%, 32.5 \%$ and $41.7 \%$ respectively. The fracture characteristics were found to be strongly related to the micro structural features. For non-modified alloys, where the Si-particles have a coarse, plate-like form, the fracture pattern was of brittle appearance. The miniature lamellar structure of eutectic-Si in Sb-modified alloy resulted in a mixed mode of fracture (brittle/ductile). Typical ductile fracture was found to be the characteristic of $\mathrm{Na}$ and Sr-modified alloys, with fibrous Si particles [3]. Pores observed in Sr-modified alloys are frequently associated with strontium oxides (films or particles). These particles/films are formed during melting, 
due to the high oxygen affinity of strontium, and are extremely difficult to be removed during degassing (using pure argon and a rotary impeller). The morphology of the pores (round or irregular) is determined by the form of oxide, i.e., fine, dispersed particles or thick films. The rounded pores are also observed surrounded by Al-Si eutectic regions [4]

\subsubsection{Grain refined and modified alloy 319}

Grain refinement is achieved through the addition of Al-Ti master alloy and/or Al-5\% Ti-1\%B master alloy in a waffle form. The addition rate is $1 \mathrm{~kg} / 1000 \mathrm{~kg}$ giving Ti and B additions of $0.005 \%$ and $0.001 \%$ respectively. Such an addition level would typically produce an equi-axed grain size of $100-150 \mathrm{~mm}$. Tial ${ }_{3}$ particles in the master alloy nucleate solid aluminium by a peritectic reaction [8].

$$
\mathrm{L}+\mathrm{tial}_{3} \rightarrow a \text {-aluminium. }
$$

$\mathrm{Tial}_{3}$ is known to be a powerful refiner. When present at hyperperitectic concentrations, dramatic grain refinement was observed and also tial 3 was found at the centres of grains with multiple orientation relationship with $\mathrm{Al}$ matrix $[5,6]$.

As cast
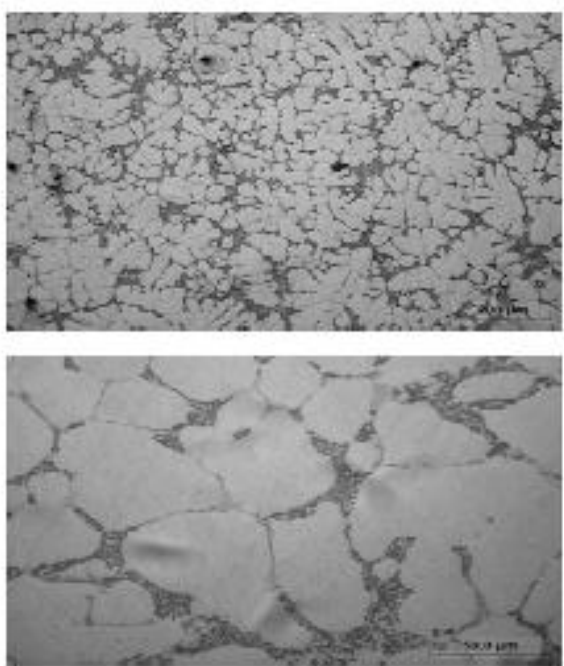

Heat troakd
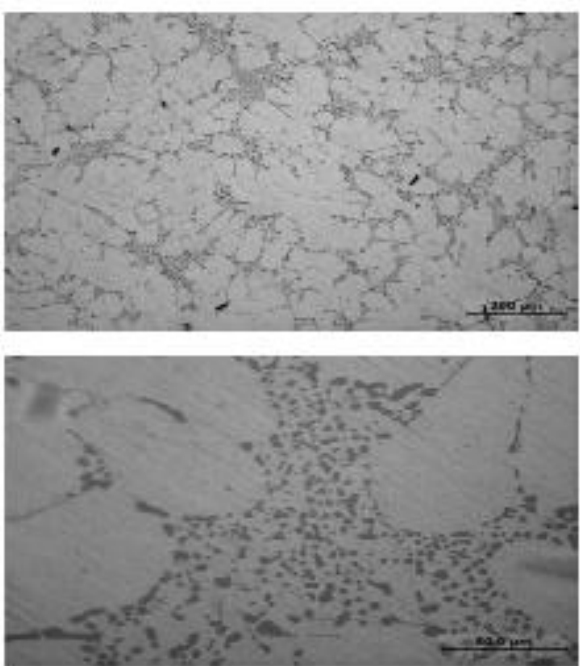

Fig.6 Modified Alloy

By the strontium addition $(0.02 \%)$, the eutectic silicon $\mathrm{Si}$ changes to fine, lamellar fibrous eutectic structure. It is seen that by heat treatment, the size of the eutectic silicon particles has decreased.

\subsubsection{4. $\mathrm{Mg}$-Sr -Ti added 319 alloy}

The microstructure shown a significant presence of $\mathrm{Q}$ phase instead of $\mathrm{Al} 2 \mathrm{Cu}$, and it is observed that besides few quantity of localized eutectic silicon phase, silicon is predominantly as an irregular black phase. Addition of $\mathrm{Mg}(\gg 0.45 \%)$ leads to the precipitation of coarse particles of $\mathrm{Al}_{5} \mathrm{Mg}_{8} \mathrm{Si}_{6} \mathrm{Cu}_{2}$. Modification with $\mathrm{Sr}$ tends to cause severe segregation of both $\mathrm{Cu}$-containing intermetallics, i.e., $\mathrm{Al}_{2} \mathrm{Cu}$ and $\mathrm{Al}_{5} \mathrm{Mg}_{8} \mathrm{Si}_{6} \mathrm{Cu}_{2}$ in areas away from the growing Al-Si eutectic regions. Thus, their dissolution rates are fairly sluggish upon solutionizing at $505 \pm \mathrm{C}$. Increasing the solutionizing temperature would lead to incipient melting of the phases and, hence, a catastrophic failure. Fracture of intermetallic phases in the interdendritic regions is mostly brittle, with the formation of microcracks at the $\mathrm{Si}, \mathrm{Cu}, \mathrm{Fe}$-base intermetallics and aluminium interfaces. Fracture of the aluminium is always ductile. Hardening during ageing occurs by cooperative precipitation of $\mathrm{Al}_{2} \mathrm{Cu}$ and $\mathrm{Mg}_{2} \mathrm{Si}$ phase particle.The $319 \mathrm{mgsrtib}$ contain an additional phase called Q-phase it may, $\mathrm{Al}_{4} \mathrm{Cu}_{2} \mathrm{Mg}_{8} \mathrm{Si}_{4}, \mathrm{Al}_{4} \mathrm{Cu}_{2} \mathrm{Mg}_{8} \mathrm{Si}_{5}$, $\mathrm{Al}_{4} \mathrm{Cu}_{2} \mathrm{Mg}_{8} \mathrm{Si}_{6}$, and $\mathrm{Al}_{4} \mathrm{Cu}_{2} \mathrm{Mg}_{8} \mathrm{Si}_{7}$. 


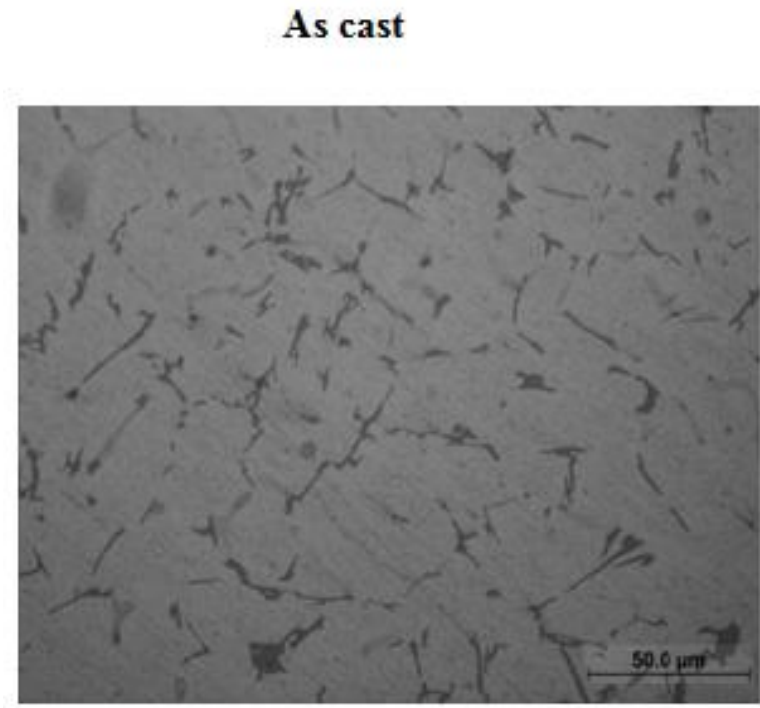

Heat treated

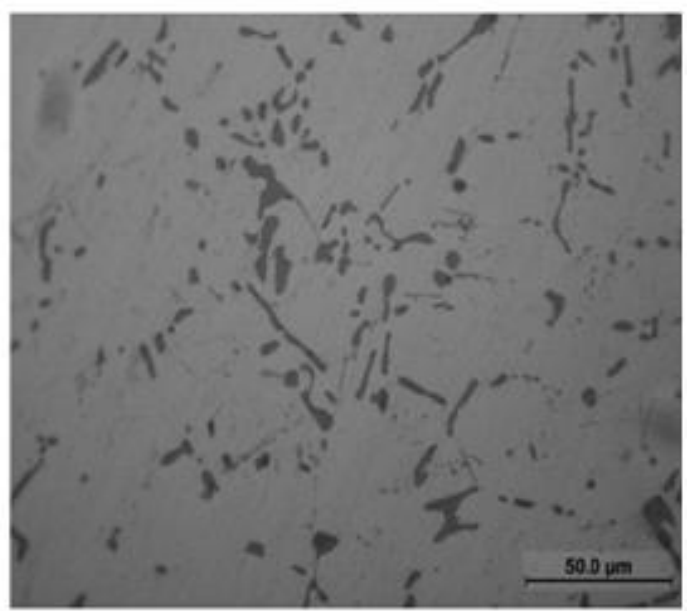

Fig.7.Mg Added Alloy

\subsection{Hardness Test}

Hardness test shows that there is increase in hardness of the alloy with additions for modification and grain refinement, further addition of magnesium in this alloy shows high results in harness. The variation in hardness is plotted above, as cast and heat treated samples are tested and plotted the hardness of $\mathrm{Mg}(0.45 \%)$ - $\mathrm{Sr}$ $(0.02 \%)$ added alloy varies from 94 and reaches a maximum at 134 . The reduction in stress concentration at particle matrix interface due to change in Si morphology which in turn increases the bonding of silicon crystals with soft eutectic matrix. Thus, the hardness of the modified alloy increases [5]. The size, morphology and distribution of the Si-particles could affect the hardness of the eutectic mixture. Consequently, the hardest alloy should have a microstructure in which fine and uniformly distributed Si-particles are present in the Al-matrix. Such microstructure seems to be obtained in the case of $\mathrm{Mg}$-Sr-modified alloy. It is concluded that for 319 alloys, about 6 hours of ageing is optimal. By cooperative precipitation of $\mathrm{Al}_{2} \mathrm{Cu}$ and $\mathrm{Mg}_{2} \mathrm{Si}$ phase particles hardening is expected to occur [1]. The silicon distribution in the matrix also accounts for the hardness. So a solutionizing temperature of $500^{\circ} \mathrm{C}$ is the appropriate temperature for this alloy. Below this temperature, the solutionization is insufficient, whereas coarsening of the Si particles and melting of $\mathrm{Al}_{2} \mathrm{Cu}$ may occur at higher temperatures [7].

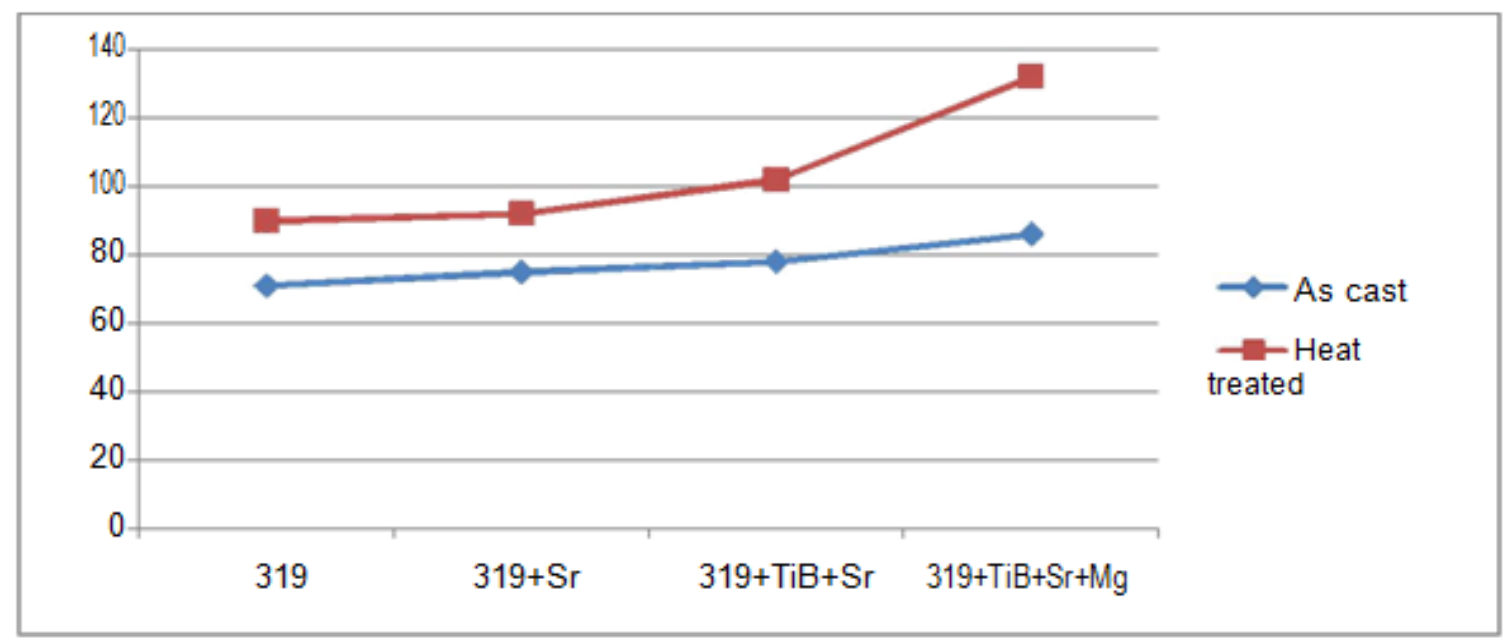

Fig.8. Hardness Graph

\subsection{Fractography}

The fractured surface revealed that fatigue crack was initiated at the specimen surface at micro pores and the crack has propagated. Once it reaches near other surface of the specimen, the specimen had failed catastrophically because the cross section of the remaining area was no longer able to carry the applied load. As understood from the literature, the most likely factor for initiation of micro cracks is the silicon particles. The 
average inter-particle spacing increases with the solution heat treatment time or temperature in all the locations of the specimens. Therefore, in heat-treated specimens, the fracture follows a path of "isolated" Si and intermetallic particles, however, the average inter-particle spacing is lower. Decohesion at low strain on the Al matrix/a-Al and the Al matrix/Si particle interface takes also place. The nucleation of cracks through the coalescence of adjacent micro cracks created during the fracture of $\mathrm{Si}$ and intermetallic particles takes place and slip bands appear between adjacent cracks. The necking along the slip bands between the micro cracks is the main mechanism for their coalescence, and the micro crack coalescence is the origin of the reduction of the load-bearing area. Micro crack coalescence is observed only after slip bands have formed between them and not due to their expansion or growth [8]. The fracture surface reveals the brittle or cleavage rupture of the silicon flakes. Initiation of crack is found to take place mostly in the silicon phase rather than the aluminium-silicon interfaces. The fracture of $a$ aluminium is ductile as evident from the dimple formation.

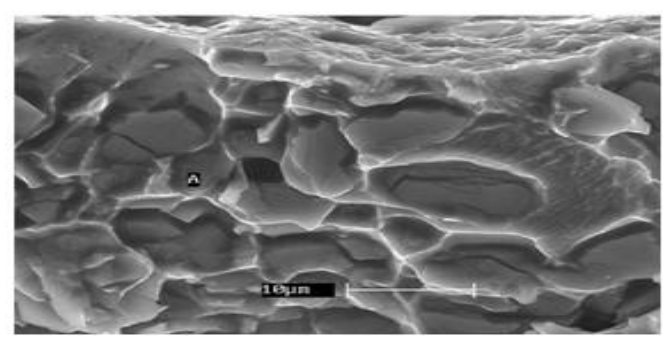

Fig.9. Mixed Cellular Fracture.
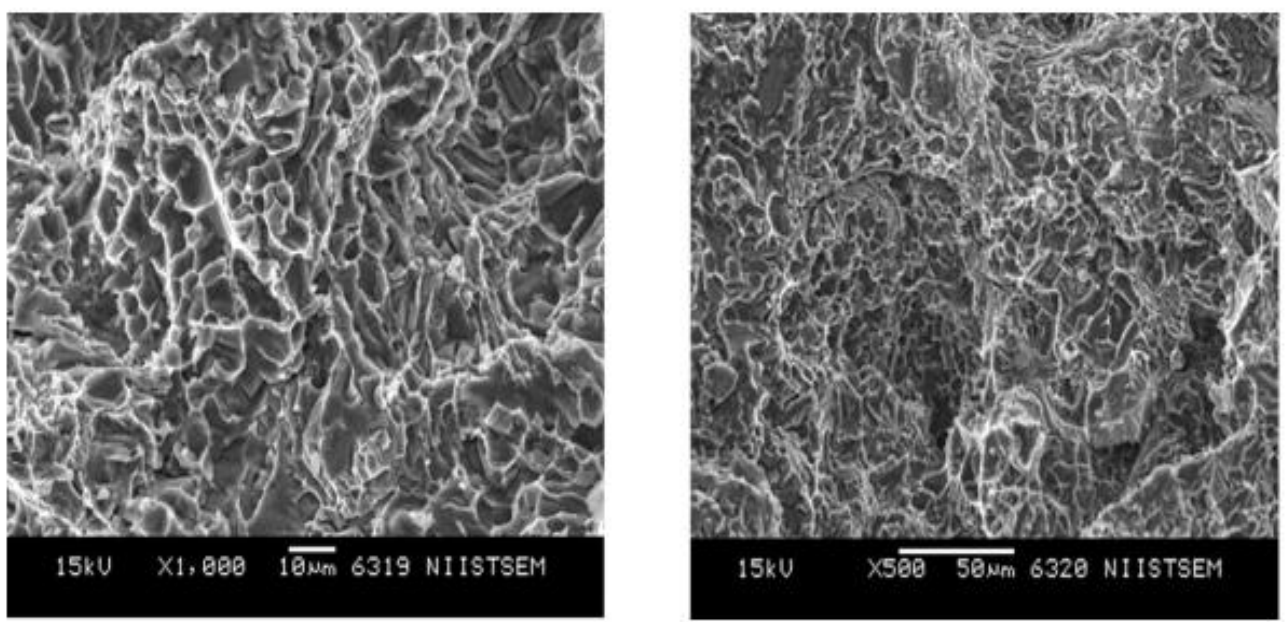

Fig.11 319 +Tib+Sr+Mg Tensile Sample Fractrography

\subsection{Conclusion}

This study mainly focused on the optimum amount of Magnesium addition in 319 aluminum alloy, the test was carried out with five different composition of magnesium in the base alloy say $0.2,0.4,0.45$, and 0.6 percentages are taken and microstructure of the base alloy with magnesium addition shows there is an additional phase called Q-phase is formed with the increase in percentage addition of magnesium and base alloy phase of $\mathrm{Al}_{2} \mathrm{Cu}$ transforms with higher percentages. The tensile test shows that with the magnesium addition the ultimate tensile strength and yield strength increases up to $0.45 \%$ of magnesium addition. T6 treatment over this composition shows good results in both ultimate tensile strength and yield strength. In case of elongation the Magnesium addition decreases the elongation due to the formation of brittle phases, the base alloy with modifications shows the better results .Hardness increases with the modification and magnesium addition. The fractrographic studies show ductile fracture for the alloy with additions due to the aluminum dendritic structure.

\section{References}

[1]. T Kashyap and T Chandrasekhar, Effects and mechanisms of grain refinement in aluminium alloys, Mater. Sci., Vol. 24, No. 4, August 2001, pp. 345-353.

[2]. B. Sua rez-Pen, J. Asensio-Lozano, Influence of Sr modification and Ti grain refinement on the morphology of Fe-rich precipitates in eutectic Al-Si die cast alloys, Scripta Materialia 54 (2006) 1543-1548.

[3]. T.R. Ramachandran, P.K. Sharma and K.Balasubramanian, Grain Refinement of Light Alloys, 68th WFC - World Foundry Congress ,7th -10th February, 2008, pp. 189-193.

[4]. F.H. Samuel, P. Ouellet, A.M. Samuel, and H.W. Doty, Effect of Mg and Sr Additions on the Formation of Intermetallics in Al-6 Wt Pct Si-3.5 Wt Pct Cu-(0.45) to (0.8)Wt Pct Fe 319-Type Alloys, Metallurgical and Materials Transactions A, , Volume 29, Issue 12,1998, pp 2871-2884 
[5]. K T Kashya, T Chandrashekar; "Effects and mechanisms of grain refinement in aluminium alloys"; Bull. Mater. Sci., Vol. 24, No. 4, August 2001, pp. 345-353.

[6]. Mark Easton and David Stjohn, "Grain refinement of aluminum alloys: Part I. The nucleant and solute paradigms-A Review of the Literature” Metallurgical and Material transactions A,30 (6),1999,1613-1623.

[7]. W. Kasprzak, C. A. Kierkus, W. T. Kierkus and J. H. Sokolowski, M. Kasprzak, W. J. Evans; The Structure and Matrix Microhardness of the 319 Aluminum Alloy After Isothermal Holding During the Solidification Process, American Foundry Society; 2001.

[8]. Crossley F A and Mondolfo L F 1951Trans. AIME 1911143. 